\title{
Platelet to Lymphocyte Ratio as a Potential Inflammatory Marker Predicting the Effect of Adjuvant Chemotherapy in Stage II Colorectal Cancer Patients
}

\section{Yu Fu}

The First Hospital of China Medical University

Xiaowan Chen

The First Hospital of China Medical University

Yongxi Song

The First Hospital of China Medical University

\section{Xuanzhang Huang}

The First Hospital of China Medical University

Quan Chen

The First Hospital of China Medical University

Xinger Lv

The First Hospital of China Medical University

\section{Peng Gao}

The First Hospital of China Medical University https://orcid.org/0000-0003-3807-2563

Zhenning Wang ( $\sim$ josieon826@sina.cn)

The First Hospital of China Medical University https://orcid.org/0000-0003-0557-3097

\section{Research article}

Keywords: colorectal cancer, stage II, adjuvant chemotherapy, inflammatory marker, platelet to lymphocyte ratio

Posted Date: November 4th, 2020

DOl: https://doi.org/10.21203/rs.3.rs-44807/v2

License: (c) (1) This work is licensed under a Creative Commons Attribution 4.0 International License. Read Full License

Version of Record: A version of this preprint was published at BMC Cancer on July 8th, 2021. See the published version at https://doi.org/10.1186/s12885-021-08521-0. 


\section{Abstract}

Background: The effect of adjuvant chemotherapy in stage II colorectal cancer (CRC) patients has been in controversy for a long time. Our study aimed to find an effective inflammatory marker to predict the effect of chemotherapy.

Methods: 708 stage II CRC patients in our institution were included. The subpopulation treatment effect pattern plot (STEPP) analysis was used to determine the optimal inflammatory marker and cut-off value. Propensity score matching (PSM) was performed to balance discrepancy between the chemotherapy and non-chemotherapy group. Survival analysis based on overall survival (OS) and cancer-specific survival (CSS) was performed using Kaplan-Meier methods with log-rank test and Cox proportional hazards regression. The restricted mean survival time (RMST) was used to measure treatment effect.

Results: Platelet to Lymphocyte Ratio (PLR) was chosen as the optimal marker with a cut-off value of 130 according to STEPP analysis. In overall survival analysis, PLR level was significantly associated with the effect of chemotherapy (interaction $\mathrm{p}=0.027$ ). In low-PLR subgroup, chemotherapy patients did not have a better OS than non-chemotherapy patients (RMST: 56.0 months vs. 56.0 months, HR: 0.983, 95 \% Cl: 0.528-1.829). In high-PLR subgroup, chemotherapy patients had a significant better OS than non-chemotherapy patients (RMST: 56.5 months vs. 51.3 months, HR: 0.371, 95\% Cl: 0.212-0.649). After PSM, PLR level was still associated with the effect of chemotherapy. In cancer-specific survival analysis, PLR level was not significantly associated with the effect of chemotherapy (interaction $p=0.116$ ). In low-PLR subgroup, chemotherapy patients did not have a better CSS than non-chemotherapy patients (RMST: 56.0 months vs. 56.0 months, HR: 1.016, 95 \% Cl: 0.494-2.087). In high-PLR subgroup, chemotherapy patients had a better CSS than nonchemotherapy patients (RMST: 56.5 months vs.51.3 months, HR: 0.371, 95\% Cl: 0.212-0.649). After PSM, PLR level was not associated with the effect of chemotherapy.

Conclusions: PLR is an effective marker to predict the effect of chemotherapy in stage II CRC patients.

\section{Background}

Colorectal cancer (CRC) is the third most commonly diagnosed cancer and ranks second in terms of mortality.[1] Radical resection is the principal curative treatment for nonmetastatic CRC patients. Adjuvant chemotherapy is a crucial means to improve additional survival benefits beyond those from surgery. Remarkably, the efficacy of adjuvant chemotherapy of patients with CRC is very likely to be stage-specific. For stage III CRC patients, adjuvant chemotherapy has already been demonstrated to be of great improvement on survival.[2, 3] However, additional survival benefit from chemotherapy in stage II CRC seems to be unclear. Many studies have been performed to find a significant survival benefit associated with chemotherapy in stage II CRC but failed. In the MOSAIC study and another study based on ACCENT database, oxaliplatinbased chemotherapy does not increase survival in the first 6 to 10 years after surgery.[4, 5] In the QUASAR study, the absolute improvement in survival after chemotherapy with fluorouracil is only 3.6\%.[6] However, there is another study demonstrating that treatment with 5-FU/LV following surgery provided significant benefit over surgery alone in stage II CRC. [7] Summarize the above and other studies, both NCCN and ASCO guidelines suggest offering chemotherapy to patients with high-risk stage II CRC.[8-12] Patients are defined as high-risk population if they have T4 depth of invasion, peritumoral lymphatic/venous invasion, histologic grade of 3 or greater, R1-R2 margin status, bowel obstruction or perforation, elevated carcinoembryonic antigen (CEA) more than $5 \mathrm{ng} / \mathrm{mL}$ or fewer than 12 nodes were retrieved. However, these high-risk characteristics are determined based on prognosis instead of additional survival benefit from chemotherapy. Guidelines also point out that there are no data that correlate risk features and selection of chemotherapy in high risk stage II patients. [13]

In the process of searching characteristics to predict chemotherapy effects of CRC and other cancers, there were many examples of inflammatory markers being used.[14-16] Inflammatory markers, including platelet to lymphocyte ratio (PLR), neutrophil to lymphocyte ratio (NLR), lymphocyte to monocyte ratio (LMR), prognostic nutritional index (PNI) and others, 
have been certificated not only strongly associated with the prognosis of cancer,[17-21] but also with chemo-resistance and chemotherapeutic responses.[22-26] Nevertheless, previous studies of inflammatory markers are focused on advanced cancers which are usually accompanied by metastasis. No studies have been performed in stage II CRC.

In this study, we aimed to investigate the ability of inflammatory markers to predict the effect of chemotherapy in stage II CRC patients and find an effective method for clinicians to distinguish the chemotherapy-effective population.

\section{Methods}

\section{Participants and criteria}

We retrospectively analyzed stage II CRC patients who received surgical treatment at the Department of Surgical Oncology and General Surgery, the First Affiliated Hospital of China Medical University between August 2010 and August 2015. All the patients enrolled in this study had undergone radical resection (R0) for the first time. Besides, part of them had received adjuvant chemotherapy and the regimen of chemotherapy was single-agent therapy with fluoropyrimidines or combination therapy with fluoropyrimidines and oxaliplatin. The single-agent therapy was given by one of following regimens: (1) Day 1: Leucovorin $400 \mathrm{mg} / \mathrm{m}^{2}$ intravenous injection (IV), followed by 5 -FU $400 \mathrm{mg} / \mathrm{m}^{2} \mathrm{IV}$ bolus, followed by $2400 \mathrm{mg} / \mathrm{m}^{2}$ as a $46-48$ hour continuous infusion. Repeat cycle every 2 weeks for 6 months perioperative therapy; (2) Days 1-14: Capecitabine $1000-1250 \mathrm{mg} / \mathrm{m}^{2}$ orally twice daily. Repeat cycle every 3 weeks for 6 months perioperative therapy. The combination therapy was given by one of following regimens: (1) Day 1: Oxaliplatin $85 \mathrm{mg} / \mathrm{m}^{2} \mathrm{IV}$ over 2 hours + leucovorin $400 \mathrm{mg} / \mathrm{m}^{2} \mathrm{IV}$ over 2 hours, followed by $5-\mathrm{FU} 400 \mathrm{mg} / \mathrm{m}^{2}$ IV bolus, followed by $2400 \mathrm{mg} / \mathrm{m}^{2}$ as a $46-48$ hour continuous infusion. Repeat cycle every 2 weeks for 6 months perioperative therapy; (2) Day 1: Oxaliplatin 130mg/m² IV. Days 1-14: Capecitabine $1000 \mathrm{mg} / \mathrm{m}^{2}$ orally twice daily. Repeat cycle every 3 weeks for 6 months perioperative therapy. All the patients were aged 18 or above and had signed informed consents and agreed to use their personal data for research. The primary inclusion criteria were as follows: (1) adenocarcinoma of colon or rectum diagnosed by histopathology, (2) stage II, high risk classified in the light of the eighth edition of the AJCC/UICC TNM classification system, (3) information of patients, including baseline characteristics, follow-up and laboratory data was integral and available. (4) all the blood samples were obtained within 1 week before the operation. Patients were removed from this study in cases of: (1) had received neoadjuvant chemotherapy, (2) had long-term use of anti-coagulant or anti-inflammatory medicine before surgery, (3) had underwent surgery in emergency circumstances, including obstruction and perforation. Follow-up was completed for all patients until December 2018. The median follow-up period was 49 months. The clinicopathological characteristics, including chemotherapy status, gender, age, tumor localization, tumor size, differentiation, $T$ category, numbers of examined lymph nodes and status of vessel carcinoma embolus and cerebrovascular and cardiovascular diseases (CCVD), and laboratory data were collected using electronic medical records. The neutrophil, platelet and lymphocyte counts were collected using a routine blood test. Albumin level was collected using the hepatic function test. PLR was defined as the absolute platelet count divided by the absolute lymphocyte count. NLR was defined as the absolute neutrophil count divided by the absolute lymphocyte count. LMR was defined as the absolute lymphocyte count divided by the absolute monocyte count. PNI was defined as $10 \times$ albumin level $(\mathrm{g} / \mathrm{dl})+0.005 \times$ lymphocyte count $(\mathrm{per} \mathrm{mm} 3)$.[27]

\section{Statistical analysis}

The Subpopulation Treatment Effect Pattern Plot (STEPP) analysis was used to determine the optimal predictive inflammatory marker and its cut-off value.[28, 29] Mann-Whitney $U$ test and the Chi-square test were used to compare the differences of the concerned inflammatory marker and the other characteristics, respectively. Our survival analysis was based on overall survival (OS) and cancer-specific survival (CSS). Kaplan-Meier method with the log-rank test was used to compare survival difference between chemotherapy and non-chemotherapy patients. Univariate Cox proportional hazard regression analysis was used to calculate Hazard Ratio (HR). Multivariate Cox proportional hazard regression analysis was used to assess the interaction between the clinicopathological characteristics and the effect of chemotherapy. 
In a survival analysis, it is difficult to calculate the survival probability at a specific time point. The restricted mean survival time (RMST) can be used as an alternative to summarize the profile.[30, 31] The RMST is defined as the mean survival time by the end of a certain time point with clinical meaning in the period of a study. It is equal to the area under the survival curve until the time point. The difference in RMST can be explained as the increase or decrease in survival time caused by a certain treatment. Consequently, the RMST can be regarded as an effective method to measure treatment effects. In our study, the RMST at 60 months calculated by Kaplan-Meier survival analysis was used.

In an observational study, it is impossible for researchers to control the treatment distribution. There may be a great difference on the covariates between treated and non-treated groups, and it is very likely to cause a bias in treatment effect estimates. In our study, propensity Score Matching (PSM) [32-34] was performed to balance the covariates in the two groups and reduce this bias.

Statistical evaluation was performed using SPSS software version 25.0 (IBM Corporation, Armonk, NY, USA) and R software version 3.6.1 (St. Louis, Missouri, USA). All statistical tests were two-sided, and a P-value of less than 0.05 was considered to indicate a statistically significant difference.

\section{Results}

\section{Patient characteristics}

After the selection, a total of 708 stage II CRC patients were included in the study. The clinicopathological characteristics of patients were summarized and compared using the Chi-square test in Table 1 and Mann-Whitney $U$ test in Table 2. 447 (63.1\%) patients received chemotherapy and 261 (36.9\%) patients did not; 431 (60.9\%) patients were male and 277 (39.1\%) were female; $354(50.0 \%)$ colon cancer patients and 354 (50.0\%) rectal cancer patients. The median age of the patients was 63 (range 23-88). According to the Chi-square test and Mann-Whitney $U$ test, there were significant differences in age, differentiation, T category, CCVD, LMR level and PNI level between the chemotherapy and non-chemotherapy patients. Higher proportions of advanced age ( $46.7 \%$ vs. $11.0 \%, p<0.001)$, poor differentiation $(9.6 \%$ vs. $6.0 \%, p=0.038)$ and positive cardio-cerebrovascular comorbidities $(16.9 \%$ vs. $10.7 \%, p=0.019)$ were seen in the non-chemotherapy patients, while the chemotherapy patients were more often diagnosed with T4 category $(67.3 \%$ vs. $54.0 \%, p<0.001)$.

\section{Optimal inflammatory marker}

STEPP analysis was performed, taking respectively the level of the four concerned inflammatory markers, including NLR, PLR, LMR and PNI, as $x$-axis and the cumulate mortality at 60 months measured by Kaplan-Meier method as y-axis to compare the OS between the chemotherapy and non-chemotherapy patients in different subgroups divided by the level of these inflammatory markers.

In the PLR-related analysis, when PLR>130, the cumulate mortality of the non-chemotherapy patients was significantly and constantly higher than the cumulate mortality of the chemotherapy patients, while the tendency was just on the contrary when PLR<130 (Figure 1A). Besides, no such tendency was found in the analyses related with the other inflammatory markers (Figure 1B, 1C and 1D). This result indicated that PLR level was closely associated with the survival benefit of chemotherapy. We could further regard PLR level of 130 as the cut-off value to distinguish chemotherapy-effective patients. Therefore, we divided the patients into high-PLR subgroup (PLR $\geq 130)$ and low-PLR subgroup (PLR<130) and performed the Chi-square test to compare PLR level between the chemotherapy and non-chemotherapy patients (Table 1).

\section{Overall survival analysis}

For all the 708 stage II CRC patients, the results of Kaplan-Meier survival analysis and univariate Cox proportional hazard regression analysis showed that the chemotherapy patients had a better OS than the non-chemotherapy patients (RMST: 56.2 months vs 53.7 months, HR: $0.580,95 \% \mathrm{Cl}$ : 0.388-0.866, Figure $2 \mathrm{~A}$ ). 
Besides, we also divided the 708 stage II CRC patients into subgroups by several characteristics including PLR level for further subgroup analysis. The results of Kaplan-Meier survival analysis and univariate Cox proportional hazard regression analysis indicated that the chemotherapy patients with these following conditions had a better OS than the nonchemotherapy patients: male (RMST: 55.9 months vs.53.2 months, HR: 0.592, 95\%Cl: 0.360-0.971), rectal cancer (RMST: 55.6 months vs. 52.2 months, HR: $0.539,95 \%$ Cl: 0.323-0.900), well or moderate differentiation (RMST: 56.3 months vs. 53.9 months, HR: $0.569,95 \%$ Cl: 0.373-0.868), T4 category (RMST: 55.6 months vs. 51.8 months, HR: 0.501, 95\% Cl: 0.3180.791), number of examined lymph nodes $\geq 12$ (RMST: 57.1 months vs. 54.5 months, HR: $0.500,95 \%$ Cl: 0.300-0.835), and PLR level>130 (RMST: 56.5 months vs.51.3 months, HR: $0.371,95 \% \mathrm{Cl}: 0.212-0.649)$. The whole results were showed in Table 3.

According to multivariate Cox proportional hazard regression analysis, PLR level was the only characteristic significantly associated with the effect of chemotherapy (interaction $\mathrm{p}=0.027$ ). In low-PLR subgroup, the chemotherapy patients did not obtain overall survival benefits over the non-chemotherapy patients (RMST: 56.0 months vs. 56.0 months, HR: $0.983,95 \%$ Cl: 0.528-1.829, Figure 2B). However, in high-PLR subgroup, the chemotherapy patients had a significant better OS than the non-chemotherapy patients (RMST: 56.5 months vs.51.3 months, HR: 0.371, 95\% Cl: 0.212-0.649, Figure 2C). The results above showed that PLR level could distinguish chemotherapy-effective population among stage II CRC patients.

\section{Overall survival analysis after PSM}

After PSM, 166 chemotherapy patients and 166 non-chemotherapy patients were paired. The characteristics of matched patients were summarized and compared in Table 4. The differences in these characteristics between the chemotherapy and non-chemotherapy patients were acceptable.

However, different from the results before PSM, the chemotherapy patients did not have a better OS than the nonchemotherapy patients (RMST: 56.0 months vs. 53.3 months, HR: 0.584, 95\% Cl: 0.333-1.025, Figure 3A). The results of subgroup analysis showed that the chemotherapy patients who were: male (RMST: 55.9 months vs.52.0 months, HR: 0.487, 95\% Cl: 0.240-0.991), T4 category (RMST: 55.2 months vs. 50.9 months, HR: 0.501, 95\% Cl: 0.267-0.939), number of examined lymph nodes $\geq 12$ (RMST: 57.5 months vs.54.1 months, HR: 0.404, 95\% Cl: 0.185-0.882) and PLR level>130 (RMST: 57.6 months vs.51.3 months, HR: $0.272,95 \%$ Cl: $0.102-0.726)$ had a better OS than the non-chemotherapy patients. The whole results were shown in Table 5.

The same as the results before PSM, PLR level was the only characteristic significantly associated with the effect of chemotherapy according to multivariate Cox survival analysis (interaction $p=0.038$ ). In low-PLR subgroup, the chemotherapy patients did not obtain overall survival benefits over the non-chemotherapy patients. (RMST: 54.9 months vs. 55.3 months, HR: 1.080, 95 \% Cl: 0.495-2.355, Figure 3B). In high-PLR subgroup, the chemotherapy patients still had a significant better OS than the non-chemotherapy patients (RMST: 57.6 months vs.51.3 months, HR: 0.272, 95\% Cl: 0.1020.726, Figure 3C). The results after PSM further confirmed the ability of PLR to predict the effect of chemotherapy measured by OS in stage II CRC patients.

\section{Cancer-specific survival analysis}

For all the 708 stage II CRC patients, the chemotherapy patients did not obtain significant cancer-specific survival benefits over the non-chemotherapy patients (RMST: 56.2 months vs 53.8 months, HR: 0.673, 95\% Cl: 0.412-1.101, Figure 4A). According to the results of subgroup analysis shown in Table 6, the chemotherapy patients who were: 66-70 years old (RMST: 57.3 months vs. 53.2 months, HR: 0.172, 95\% Cl: 0.036-0.834) and PLR level>130 (RMST: 56.5 months vs. 51.3 months, HR: $0.440,95 \% \mathrm{Cl}: 0.217-0.893$ ) had a better CSS than the non-chemotherapy patients.

The results of multivariate Cox survival analysis showed PLR level was not significantly associated with the effect of chemotherapy (interaction $\mathrm{p}=0.116$ ). However, cancer-specific survival benefits form chemotherapy between low-PLR and 
high-PLR subgroup was quite different. In low-PLR subgroup, the chemotherapy did not have a better CSS than the nonchemotherapy patients (RMST: 56.0 months vs. 56.0 months, HR: 1.016, 95 \% Cl: 0.494-2.087, Figure 4B). In high-PLR subgroup, the chemotherapy patients had a significantly better CSS than the non-chemotherapy patients (RMST: 56.5 months vs.51.3 months, HR: 0.440, 95\% Cl: 0.217-0.893, Figure 4C). The results above indicated that PLR level was related to the effect of chemotherapy measured by CSS.

\section{Cancer-specific survival analysis after PSM}

For the 332 matched patients, the chemotherapy did not have a better CSS than the non-chemotherapy patients (RMST:56.0 months vs. 53.3 months, HR: $0.684,95 \% \mathrm{Cl}$ : $0.332-1.409$, Figure $5 \mathrm{~A}$ ). According to the results of subgroup analysis shown in Table 7, there was no subgroup in which survival difference between the chemotherapy and nonchemotherapy patients was found. These results indicated that no characteristics were related to the effect of chemotherapy.

In multivariate Cox survival analysis, PLR level was not significantly associated with the effect of chemotherapy (interaction $\mathrm{p}=0.231$ ). In low-PLR subgroup, the chemotherapy patients did not have a better CSS than the nonchemotherapy patients (RMST: 54.9 months vs. 55.3 months, HR: 0.963, 95\% Cl: 0.379-2.449, Figure 5B). In high-PLR subgroup, the chemotherapy patients had a tendency of better CSS, despite not statistically significant, than the nonchemotherapy patients (RMST: 57.6 months vs. 51.3 months, HR: 0.372, 95\% Cl: 0.100-1.374, Figure 5C).

\section{Discussion}

Guidelines suggest patients with high-risk stage II CRC should receive adjuvant chemotherapy.[8-12] The NCCN guidelines define patients as high-risk population in the case of: T4 depth of invasion, peritumoral lymphatic/venous invasion, histologic grade of 3 or greater, R1-R2 margin status, bowel obstruction or perforation or fewer than 12 nodes were retrieved. Besides, patients are also defined as high-risk by the ASCO guidelines if they have elevated carcinoembryonic antigen (CEA) (CEA $>5 \mathrm{ng} / \mathrm{ml})$. Although these high-risk characteristics determined by overall survival benefit can distinguish the population with poorer prognosis from all stage II CRC patients, they cannot predict additional survival benefit from chemotherapy of the population. Considering the statistical-significance-lacking difference in survival between the chemotherapy and non-chemotherapy population and the side effects chemotherapy may cause[35, 36], chemotherapy may do more harm than good for certain stage II CRC patients. Given this background, novel biomarkers are required to distinguish chemotherapy-effective population among patients with stage II CRC.

There are substantial evidence showing that the progression of a tumor depends on not only the tumor itself, but also the inflammatory response of the host.[37] The inflammatory response has been proved to lead to an impaired immune function and an anti-tumor immune response of the host. It has been widely accepted as an important stage-independent indicator, especially in renal, gastro-esophageal and colorectal cancers. In fact, inflammatory cells, such as neutrophil, lymphocyte, platelet and monocyte, have already been used in prognostic prediction for CRC patients. $[17,19,21,38]$ Furthermore, some studies also proved the interaction between inflammation and the response and resistance of chemotherapy.[22-26, 39] The results of these studies indicate that predicting the treatment effect of chemotherapy with inflammatory biomarkers is feasible.

As an important member of inflammatory markers, many studies have been performed to explore the clinical application of PLR. Several studies found elevated PLR was a prognostic indicator of poor prognosis in CRC patients.[19,40] However, the clinical application of PLR in stage II CRC patients was still controversial. The study of Ozawa et al. indicated that PLR could be used as a prognostic marker in stage II CRC patients who had undergone curative surgery but not adjuvant chemotherapy.[41] Some studies showed elevated PLR was significantly associated with poor survival in both stage II and III CRC [42,43], while the study of You et al. showed PLR was associated with survival outcomes in stage III CRC but not in 
stage II CRC.[44] It is noteworthy that most studies of PLR's clinical application are focused on prognosis but not the effect of chemotherapy. Our study aiming at chemotherapy guidance is quite different form these studies.

As far as we know, our study is the first to predict the effect of chemotherapy in stage II CRC patients. We found that the PLR level was the only characteristic associated with chemotherapy status among all the characteristics including other inflammatory markers. Patients with elevated PLR could obtain a significant survival benefit from chemotherapy while patients with reduced PLR could not. The results demonstrated that PLR had the ability to predict the effect of chemotherapy and distinguish the chemotherapy-effective population in stage II CRC patients. Besides, we also found something in our results which were different from guidelines and previous studies. According to guidelines, stage II CRC patients with poor pathological differentiation or inadequate nodal resection are suggested receive chemotherapy, while this population did not obtain a survival benefit from chemotherapy in our study. The possible reasons of the contradictory results are regarded as follows: Firstly, selection bias caused by the retrospective and single-center nature of our study. Secondly, insufficient sample size of these subgroups. Thirdly, patients with poor pathological differentiation and inadequate nodal resection are indeed not significantly chemotherapy-effective, even though they are suggested receive chemotherapy. The inability to analyze the role of bowel obstruction and perforation and chemotherapy regimen is also a limitation to our study. Inflammatory-related indicators, such as neutrophil, platelet, lymphocyte count and albumin level, would largely deviate from the general level in the setting of bowel obstruction or perforation, so patients with bowel obstruction or perforation were excluded from our analysis. Because of the relatively smaller number of patients received single-agent therapy, we only compared survival benefits between chemotherapy and non-chemotherapy patients, further comparison between patients with different chemotherapy regimens was not performed. Besides, according to the results of cancer-specific survival analysis, PLR level was not so significantly associated with the effect of chemotherapy as the results of overall survival analysis. The relatively small number of events caused by the insufficient sample size and good prognosis of our study may be the reason of the different results between OS and CSS.

Up to now, many studies have been conducted to explore the role of lymphocyte and platelet in tumor progression. Platelets promote angiogenesis, adhesion, and invasion by secreting angiogenic and tumor growth factors, such as transforming growth factor-beta (TGF $\beta$ ) and vascular epidermal growth factor (VEGF), in a tumor environment.[45-47] Platelets have also been proved to prevent the death of tumor cells by natural killer cells.[48] Besides, platelets can promote other immune cells, such as lymphocytes and neutrophils, to infiltrate into tumor tissues and trigger further inflammatory progress by releasing chemokines and cytokines.[49] Consequently, a high level of platelet can partly reflect systemic inflammation and increased meta-statization of neoplastic cells.[50,51] Lymphocytes are the main components of the immune defense to malignancy of the host and can induce cytotoxic cell death and inhibit tumor cell proliferation and migration. $[52,53]$ Therefore, a low level of lymphocyte can partly reflect an impaired activation of adaptive immunity and poor nutritional status.[54,55] These studies mentioned above did not directly elaborate the mechanisms of lymphocyte and platelet in chemotherapy but truly provided some ideas for our research.

For the significant association between elevated PLR and effective chemotherapy treatment shown in our study, we raised three possible explanations. First, previous clinical studies have proved that CRC patients with elevated PLR may have a poorer prognosis and shorter postoperative survival time than the other patients.[19,40-44] Considering high-risk patients usually needed additional therapy, it may be one of the reasons why they can obtain more additional survival benefit from chemotherapy. Second, platelets have been demonstrated to be critical for maintaining tumor vascular generation and integrity.[56] To go a step further, high platelets may be related with a rich network of tumor vessels and increased chemotherapeutic agent transport into the tumor and lead to effective chemotherapy treatment. In fact, improving vascular function has long been discussed as a possibility to improve the treatment effect of chemotherapy.[57] Third, as a common side effect of chemotherapy, myelosuppression is an important factor for the continuation of chemotherapy in clinical practice. In chemotherapy of CRC, both two frequently-used agents, oxaliplatin and capecitabine, have been proved to be inducers of myelosuppression, including thrombocytopenia.[58-61] Patients with elevated PLR may have greater 
tolerance against chemotherapy than the other patients so that they can receive longer and large dose of chemotherapy. This can explain association between elevated PLR and effective chemotherapy treatment.

Our results indicated a positive association between elevated PLR and effective chemotherapy treatment in stage II CRC patients. PLR showed potential as a practical, inexpensive, highly reliable and easily available marker to predict the effect of chemotherapy and distinguish chemotherapy-effective population. However, the potential mechanisms and the specific predictive capacity of PLR should be validated in further prospective, larger population and multi-center studies.

\section{Conclusions}

In conclusion, our study found that the PLR was significantly associated with effect of chemotherapy in stage II CRC patients. Patients with elevated PLR level $(P L R>130)$ could obtain great survival benefits from chemotherapy while patients with reduced PLR level (PLR $\leq 130)$ could not. PLR can be used as an effective inflammatory marker to predict effect of chemotherapy and distinguish chemotherapy-effective population in stage II CRC patients.

\section{Declarations}

\section{Ethics approval and consent to participate}

The study involving human participants was reviewed and approved by the ethics committees of the First Affiliated Hospital of China Medical University. The patients provided their written informed consent to participate in this study.

\section{Consent to publish}

Not applicable

\section{Availability of data and materials}

All data generated and analyzed during this study are included in this published article and its supplementary information files.

\section{Competing interests}

The authors declare that they have no competing interests.

\section{Funding}

This work was supported by the grants from Natural Science Foundation of Liaoning Province of China (2019-MS-390), Liaoning Province Central Guided Local Science and Technology Development Special Fund (2018107004), Overseas Training Program for Higher Learning Institutions of Liaoning Province (2019GJWYB022) and Major Scientific and Technological Special Project of Liaoning Province of China (2019JH1/10300007).

\section{Authors' Contributions}

PG and ZW formulated the research question. XC and QC collected the bulk of data profiles, YF drafted the full manuscript. YS provided substantial input in planning and revising the manuscript. PG provided statistical support and made revision to the results section of the manuscript. $\mathrm{XH}$ and $\mathrm{XC}$ contributed revisions to the introduction and the discussion. $\mathrm{LX}$ conducted analyses and sorted parts of the methods section. ZW played a crucial role in the design of the research and provided revision to this text. All authors contributed to manuscript revision, read and approved the submitted version.

\section{Acknowledgements}


We thank Yiducloud (Beijing) Technology Ltd for supporting part of the data extraction and processing. The corresponding author had full access to all the data and analyses.

\section{Abbreviations}

CRC: colorectal cancer; CEA: carcinoembryonic antigen; CCVD: cerebrovascular and cardiovascular diseases; PLR: platelet to lymphocyte ratio; NLR: neutrophil to lymphocyte ratio; LMR: lymphocyte to monocyte ratio; PNI: prognostic nutritional index; STEPP: Subpopulation Treatment Effect Pattern Plot; OS: overall survival; HR: Hazard Ratio; RMST: restricted mean survival time; PSM: Propensity Score Matching; TGF $\beta$ : transforming growth factor-beta; VEGF: vascular epidermal growth factor; Cl: Confidence interval

\section{References}

[1] F. Bray, J. Ferlay, I. Soerjomataram, R.L. Siegel, L.A. Torre, and A. Jemal. (2018). Global cancer statistics 2018: GLOBOCAN estimates of incidence and mortality worldwide for 36 cancers in 185 countries. CA: a cancer journal for clinicians 68. 394-424. doi: 10.3322/caac.21492.

[2] D. Sargent, A. Sobrero, A. Grothey, M.J. O'Connell, M. Buyse, T. Andre, et al. (2009). Evidence for cure by adjuvant therapy in colon cancer: observations based on individual patient data from 20,898 patients on 18 randomized trials. Journal of clinical oncology : official journal of the American Society of Clinical Oncology 27. 872-7. doi: 10.1200/jco.2008.19.5362.

[3] C.M. Booth, S. Nanji, X. Wei, Y. Peng, J.J. Biagi, T.P. Hanna, et al. (2016). Use and Effectiveness of Adjuvant Chemotherapy for Stage III Colon Cancer: A Population-Based Study. Journal of the National Comprehensive Cancer Network : JNCCN 14. 47-56. doi: 10.6004/jnccn.2016.0006.

[4] T. Andre, A. de Gramont, D. Vernerey, B. Chibaudel, F. Bonnetain, A. Tijeras-Raballand, et al. (2015). Adjuvant Fluorouracil, Leucovorin, and Oxaliplatin in Stage II to III Colon Cancer: Updated 10-Year Survival and Outcomes According to BRAF Mutation and Mismatch Repair Status of the MOSAIC Study. Journal of clinical oncology : official journal of the American Society of Clinical Oncology 33. 4176-87. doi: 10.1200/jco.2015.63.4238.

[5] M.A. Shah, L.A. Renfro, C.J. Allegra, T. Andre, A. de Gramont, H.J. Schmoll, et al. (2016). Impact of Patient Factors on Recurrence Risk and Time Dependency of Oxaliplatin Benefit in Patients With Colon Cancer: Analysis From Modern-Era Adjuvant Studies in the Adjuvant Colon Cancer End Points (ACCENT) Database. Journal of clinical oncology : official journal of the American Society of Clinical Oncology 34. 843-53. doi: 10.1200/jco.2015.63.0558.

[6] R. Gray, J. Barnwell, C. McConkey, R.K. Hills, N.S. Williams, and D.J. Kerr. (2007). Adjuvant chemotherapy versus observation in patients with colorectal cancer: a randomised study. Lancet (London, England) 370. 2020-9. doi: 10.1016/s0140-6736(07)61866-2.

[7] N.W. Wilkinson, G. Yothers, S. Lopa, J.P. Costantino, N.J. Petrelli, and N. Wolmark. (2010). Long-term survival results of surgery alone versus surgery plus 5-fluorouracil and leucovorin for stage II and stage III colon cancer: pooled analysis of NSABP C-01 through C-05. A baseline from which to compare modern adjuvant trials. Annals of surgical oncology 17. 95966. doi: 10.1245/s10434-009-0881-y.

[8] A. Costas-Chavarri, G. Nandakumar, S. Temin, G. Lopes, A. Cervantes, M. Cruz Correa, et al. (2019). Treatment of Patients With Early-Stage Colorectal Cancer: ASCO Resource-Stratified Guideline. Journal of global oncology 5. 1-19. doi: 10.1200/jgo.18.00214.

[9] J. Kannarkatt, J. Joseph, P.C. Kurniali, A. Al-Janadi, and B. Hrinczenko. (2017). Adjuvant Chemotherapy for Stage II Colon Cancer: A Clinical Dilemma. Journal of oncology practice 13. 233-241. doi: 10.1200/jop.2016.017210.

Page 9/29 
[10] G.M. Boland, G.J. Chang, A.B. Haynes, Y.J. Chiang, R. Chagpar, Y. Xing, et al. (2013). Association between adherence to National Comprehensive Cancer Network treatment guidelines and improved survival in patients with colon cancer. Cancer 119. 1593-601. doi: 10.1002/cncr.27935.

[11] L. Casadaban, G. Rauscher, M. Aklilu, D. Villenes, S. Freels, and A.V. Maker. (2016). Adjuvant chemotherapy is associated with improved survival in patients with stage II colon cancer. Cancer 122. 3277-3287. doi: 10.1002/cncr.30181.

[12] R.B. Hines, A. Barrett, P. Twumasi-Ankrah, D. Broccoli, K.K. Engelman, J. Baranda, et al. (2015). Predictors of guideline treatment nonadherence and the impact on survival in patients with colorectal cancer. Journal of the National Comprehensive Cancer Network : JNCCN 13. 51-60. doi: 10.6004/jnccn.2015.0008.

[13] A.B. Benson, A.P. Venook, M.M. Al-Hawary, L. Cederquist, Y.J. Chen, K.K. Ciombor, et al. (2018). NCCN Guidelines Insights: Colon Cancer, Version 2.2018. Journal of the National Comprehensive Cancer Network : JNCCN 16. 359-369. doi: 10.6004/jnccn.2018.0021.

[14] J. Jiang, T. Ma, W. Xi, C. Yang, J. Wu, C. Zhou, et al. (2019). Pre-treatment inflammatory biomarkers predict early treatment response and favorable survival in patients with metastatic colorectal cancer who underwent first line cetuximab plus chemotherapy. Cancer management and research 11. 8657-8668. doi: 10.2147/cmar.S211089.

[15] I.H. Kim, J.E. Lee, J.H. Yang, J.W. Jeong, S. Ro, and M.A. Lee. (2018). Clinical significance of changes in systemic inflammatory markers and carcinoembryonic antigen levels in predicting metastatic colorectal cancer prognosis and chemotherapy response. Asia-Pacific journal of clinical oncology 14. 239-246. doi: 10.1111/ajco.12784.

[16] M. Shibutani, H. Nagahara, T. Fukuoka, Y. Iseki, K. Hirakawa, and M. Ohira. (2019). Efficacy of Adjuvant Chemotherapy According to the Classification of Recurrence Risk Based on Systemic Inflammatory Markers in Patients With Liver Metastases of Colorectal Cancer. Anticancer research 39. 5039-5045. doi: 10.21873/anticanres.13695.

[17] M.X. Li, X.M. Liu, X.F. Zhang, J.F. Zhang, W.L. Wang, Y. Zhu, et al. (2014). Prognostic role of neutrophil-to-lymphocyte ratio in colorectal cancer: a systematic review and meta-analysis. International journal of cancer 134. 2403-13. doi: $10.1002 / \mathrm{ijc} .28536$.

[18] J. Sun, X. Chen, P. Gao, Y. Song, X. Huang, Y. Yang, et al. (2016). Can the Neutrophil to Lymphocyte Ratio Be Used to Determine Gastric Cancer Treatment Outcomes? A Systematic Review and Meta-Analysis. Disease markers 2016. 7862469. doi: 10.1155/2016/7862469.

[19] C. Lu, P. Gao, Y. Yang, X. Chen, L. Wang, D. Yu, et al. (2017). Prognostic evaluation of platelet to lymphocyte ratio in patients with colorectal cancer. Oncotarget 8. 86287-86295. doi: 10.18632/oncotarget.21141.

[20] Y. Yang, P. Gao, Y. Song, J. Sun, X. Chen, J. Zhao, et al. (2016). The prognostic nutritional index is a predictive indicator of prognosis and postoperative complications in gastric cancer: A meta-analysis. European journal of surgical oncology : the journal of the European Society of Surgical Oncology and the British Association of Surgical Oncology 42. 1176-82. doi: 10.1016/j.ejso.2016.05.029.

[21] J.C. Chan, D.L. Chan, C.I. Diakos, A. Engel, N. Pavlakis, A. Gill, et al. (2017). The Lymphocyte-to-Monocyte Ratio is a Superior Predictor of Overall Survival in Comparison to Established Biomarkers of Resectable Colorectal Cancer. Annals of surgery 265. 539-546. doi: 10.1097/sla.0000000000001743.

[22] K.E. de Visser, and J. Jonkers. (2009). Towards understanding the role of cancer-associated inflammation in chemoresistance. Current pharmaceutical design 15. 1844-53. doi: 10.2174/138161209788453239. 
[23] M. Jinushi, and Y. Komohara. (2015). Tumor-associated macrophages as an emerging target against tumors: Creating a new path from bench to bedside. Biochimica et biophysica acta 1855. 123-30. doi: 10.1016/j.bbcan.2015.01.002.

[24] H. Sun, P. Hu, J. Du, and X. Wang. (2018). Predictive value of inflammatory indexes on the chemotherapeutic response in patients with unresectable lung cancer: A retrospective study. Oncology letters 15. 4017-4025. doi: 10.3892/ol.2018.7781.

[25] R.D. Sanderson, M. Elkin, A.C. Rapraeger, N. Ilan, and I. Vlodavsky. (2017). Heparanase regulation of cancer, autophagy and inflammation: new mechanisms and targets for therapy. The FEBS journal 284. 42-55. doi: 10.1111/febs.13932.

[26] K.P. Olive. (2017). Fanning the Flames of Cancer Chemoresistance: Inflammation and Anticancer Therapy. Journal of oncology practice 13. 181-183. doi: 10.1200/jop.2017.021154.

[27] T. Onodera, N. Goseki, and G. Kosaki. (1984). [Prognostic nutritional index in gastrointestinal surgery of malnourished cancer patients]. Nihon Geka Gakkai zasshi 85. 1001-5. doi:

[28] M. Bonetti, and R.D. Gelber. (2004). Patterns of treatment effects in subsets of patients in clinical trials. Biostatistics (Oxford, England) 5. 465-81. doi: 10.1093/biostatistics/5.3.465.

[29] A.A. Lazar, B.F. Cole, M. Bonetti, and R.D. Gelber. (2010). Evaluation of treatment-effect heterogeneity using biomarkers measured on a continuous scale: subpopulation treatment effect pattern plot. Journal of clinical oncology : official journal of the American Society of Clinical Oncology 28. 4539-44. doi: 10.1200/jco.2009.27.9182.

[30] L. Zhao, B. Claggett, L. Tian, H. Uno, M.A. Pfeffer, S.D. Solomon, et al. (2016). On the restricted mean survival time curve in survival analysis. Biometrics 72. 215-21. doi: 10.1111/biom.12384.

[31] X. Wang, and D.E. Schaubel. (2018). Modeling restricted mean survival time under general censoring mechanisms. Lifetime data analysis 24. 176-199. doi: 10.1007/s10985-017-9391-6.

[32] R.J. Little, and D.B. Rubin. (2000). Causal effects in clinical and epidemiological studies via potential outcomes: concepts and analytical approaches. Annual review of public health 21. 121-45. doi:

10.1146/annurev.publhealth.21.1.121.

[33] D.B. Rubin. (1997). Estimating causal effects from large data sets using propensity scores. Annals of internal medicine 127. 757-63. doi: 10.7326/0003-4819-127-8_part_2-199710151-00064.

[34] R.B. D'Agostino, Jr. (1998). Propensity score methods for bias reduction in the comparison of a treatment to a nonrandomized control group. Statistics in medicine 17. 2265-81. doi: 10.1002/(sici)1097-0258(19981015)17:19<2265::aid$\operatorname{sim} 918>3.0 . c 0 ; 2-b$.

[35] H.S. Hochster, L.L. Hart, R.K. Ramanathan, B.H. Childs, J.D. Hainsworth, A.L. Cohn, et al. (2008). Safety and efficacy of oxaliplatin and fluoropyrimidine regimens with or without bevacizumab as first-line treatment of metastatic colorectal cancer: results of the TREE Study. Journal of clinical oncology : official journal of the American Society of Clinical Oncology 26. 3523-9. doi: 10.1200/jco.2007.15.4138.

[36] S. Dueland, A.H. Ree, K.K. Groholt, M.G. Saelen, S. Folkvord, K.H. Hole, et al. (2016). Oxaliplatin-containing Preoperative Therapy in Locally Advanced Rectal Cancer: Local Response, Toxicity and Long-term Outcome. Clinical oncology (Royal College of Radiologists (Great Britain)) 28. 532-9. doi: 10.1016/j.clon.2016.01.014.

[37] C.S. Roxburgh, and D.C. McMillan. (2010). Role of systemic inflammatory response in predicting survival in patients with primary operable cancer. Future oncology (London, England) 6. 149-63. doi: 10.2217/fon.09.136.

Page $11 / 29$ 
[38] J. Yang, H. Xu, X. Guo, J. Zhang, X. Ye, Y. Yang, et al. (2018). Pretreatment Inflammatory Indexes as Prognostic Predictors for Survival in Colorectal Cancer Patients Receiving Neoadjuvant Chemoradiotherapy. Scientific reports 8.3044. doi: 10.1038/s41598-018-21093-7.

[39] M. Murata. (2018). Inflammation and cancer. Environmental health and preventive medicine 23. 50. doi: 10.1186/s12199-018-0740-1.

[40] Kwon HC, Kim SH, Oh SY, Lee S, Lee JH, Choi HJ, et al. Clinical significance of preoperative neutrophil-lymphocyte versus platelet-lymphocyte ratio in patients with operable colorectal cancer. Biomarkers : biochemical indicators of exposure, response, and susceptibility to chemicals. 2012;17(3):216-22. doi: 10.3109/1354750X.2012.656705.

[41] Ozawa T, Ishihara S, Nishikawa T, Tanaka T, Tanaka J, Kiyomatsu T, et al. The preoperative platelet to lymphocyte ratio is a prognostic marker in patients with stage II colorectal cancer. International journal of colorectal disease. 2015;30(9):1165-71. doi: 10.1007/s00384-015-2276-9.

[42] Szkandera J, Pichler M, Absenger G, Stotz M, Arminger F, Weissmueller M, et al. The elevated preoperative platelet to lymphocyte ratio predicts decreased time to recurrence in colon cancer patients. American journal of surgery. 2014;208(2):210-4. doi: 10.1016/j.amjsurg.2013.10.030.

[43] Lee IH, Hwang S, Lee SJ, Kang BW, Baek D, Kim HJ, et al. Systemic Inflammatory Response After Preoperative Chemoradiotherapy Can Affect Oncologic Outcomes in Locally Advanced Rectal Cancer. Anticancer research. 2017;37(3):1459-65. doi: 10.21873/anticanres.11470.

[44] You J, Zhu GQ, Xie L, Liu WY, Shi L, Wang OC, et al. Preoperative platelet to lymphocyte ratio is a valuable prognostic biomarker in patients with colorectal cancer. Oncotarget. 2016;7(18):25516-27. doi: 10.18632/oncotarget.8334.

[45] M. Labelle, S. Begum, and R.O. Hynes. (2011). Direct signaling between platelets and cancer cells induces an epithelialmesenchymal-like transition and promotes metastasis. Cancer cell 20. 576-90. doi: 10.1016/j.ccr.2011.09.009.

[46] L.J. Gay, and B. Felding-Habermann. (2011). Contribution of platelets to tumour metastasis. Nature reviews. Cancer 11. 123-34. doi: $10.1038 /$ nrc3004.

[47] T. Tsuji, T. Sawai, H. Yamashita, H. Takeshita, T. Nakagoe, H. Shindou, et al. (2004). Platelet-derived endothelial cell growth factor expression is an independent prognostic factor in colorectal cancer patients after curative surgery. European journal of surgical oncology : the journal of the European Society of Surgical Oncology and the British Association of Surgical Oncology 30. 296-302. doi: 10.1016/j.ejso.2003.11.019.

[48] J.S. Palumbo, K.E. Talmage, J.V. Massari, C.M. La Jeunesse, M.J. Flick, K.W. Kombrinck, et al. (2005). Platelets and fibrin(ogen) increase metastatic potential by impeding natural killer cell-mediated elimination of tumor cells. Blood 105. 178-85. doi: 10.1182/blood-2004-06-2272.

[49] C.N. Jenne, R. Urrutia, and P. Kubes. (2013). Platelets: bridging hemostasis, inflammation, and immunity. International journal of laboratory hematology 35. 254-61. doi: 10.1111/ijlh.12084.

[50] S. Raungkaewmanee, S. Tangjitgamol, S. Manusirivithaya, S. Srijaipracharoen, and T. Thavaramara. (2012). Platelet to lymphocyte ratio as a prognostic factor for epithelial ovarian cancer. Journal of gynecologic oncology 23. 265-73. doi: 10.3802/jgo.2012.23.4.265.

[51] C.S. Roxburgh, and D.C. McMillan. (2014). Cancer and systemic inflammation: treat the tumour and treat the host. British journal of cancer 110. 1409-12. doi: 10.1038/bjc.2014.90. 
[52] U. De Giorgi, M. Mego, E. Scarpi, M. Giuliano, A. Giordano, J.M. Reuben, et al. (2012). Relationship between lymphocytopenia and circulating tumor cells as prognostic factors for overall survival in metastatic breast cancer. Clinical breast cancer 12. 264-9. doi: 10.1016/j.clbc.2012.04.004.

[53] S.A. Rosenberg. (2001). Progress in human tumour immunology and immunotherapy. Nature 411. 380-4. doi: $10.1038 / 35077246$.

[54] D.D. Wagner. (2005). New links between inflammation and thrombosis. Arteriosclerosis, thrombosis, and vascular biology 25. 1321-4. doi: 10.1161/01.Atv.0000166521.90532.44.

[55] R.L. Gross, and P.M. Newberne. (1980). Role of nutrition in immunologic function. Physiological reviews 60. $188-302$. doi: 10.1152/physrev.1980.60.1.188.

[56] J. Volz, E. Mammadova-Bach, J. Gil-Pulido, R. Nandigama, K. Remer, L. Sorokin, et al. (2019). Inhibition of platelet GPVI induces intratumor hemorrhage and increases efficacy of chemotherapy in mice. Blood 133. 2696-2706. doi: 10.1182/blood.2018877043.

[57] R.K. Jain. (2005). Normalization of tumor vasculature: an emerging concept in antiangiogenic therapy. Science (New York, N.Y.) 307. 58-62. doi: 10.1126/science.1104819.

[58] M.S. Beg, R.S. Komrokji, K. Ahmed, and M.M. Safa. (2008). Oxaliplatin-induced immune mediated thrombocytopenia. Cancer chemotherapy and pharmacology 62. 925-7. doi: 10.1007/s00280-007-0675-5.

[59] B.R. Curtis, J. Kaliszewski, M.B. Marques, M.W. Saif, L. Nabelle, J. Blank, et al. (2006). Immune-mediated thrombocytopenia resulting from sensitivity to oxaliplatin. American journal of hematology 81. 193-8. doi: 10.1002/ajh.20516.

[60] Y. Ito, S. Kobuchi, R. Shimizu, and Y. Katsuyama. (2018). Pharmacokinetic and toxicodynamic evaluation of oxaliplatininduced neuropathy and hematological toxicity in rats. Cancer chemotherapy and pharmacology 81. 155-161. doi: 10.1007/s00280-017-3485-4.

[61] A.S. Zandvliet, W.S. Siegel-Lakhai, J.H. Beijnen, W. Copalu, M.C. Etienne-Grimaldi, G. Milano, et al. (2008). PK/PD model of indisulam and capecitabine: interaction causes excessive myelosuppression. Clinical pharmacology and therapeutics 83. 829-39. doi: 10.1038/sj.clpt.6100344.

\section{Tables}

Table 1 Characteristics of non-chemotherapy and chemotherapy group 


\begin{tabular}{|c|c|c|c|c|c|}
\hline \multirow[t]{2}{*}{ Characteristics } & & Total & Non-Chemotherapy & Chemotherapy & $\mathrm{P}_{\text {value }} \mathrm{a}^{\mathrm{a}}$ \\
\hline & & 708 & 261 & 447 & \\
\hline \multirow[t]{2}{*}{ Gender } & Male & $431(60.9 \%)$ & $156(59.8 \%)$ & $275(61.5 \%)$ & 0.645 \\
\hline & Female & 277 (39.1\%) & 105 (40.2\%) & 172 (38.5\%) & \\
\hline \multirow[t]{5}{*}{ Age (years) } & $\leq 55$ & $163(23.0 \%)$ & $32(12.3 \%)$ & $131(29.3 \%)$ & $<0.001$ \\
\hline & $56-60$ & $125(17.7 \%)$ & $23(8.8 \%)$ & $102(22.8 \%)$ & \\
\hline & $61-65$ & $146(20.6 \%)$ & $40(15.3 \%)$ & $106(23.7 \%)$ & \\
\hline & $66-70$ & $103(14.5 \%)$ & $44(16.9 \%)$ & $59(13.2 \%)$ & \\
\hline & $>70$ & $171(24.2 \%)$ & $122(46.7 \%)$ & $49(11.0 \%)$ & \\
\hline \multirow[t]{2}{*}{ Location } & Rectum & 354 (50.0\%) & $119(45.6 \%)$ & 235 (52.6\%) & 0.073 \\
\hline & Colon & 354 (50.0\%) & $142(54.4 \%)$ & $212(47.4 \%)$ & \\
\hline \multirow[t]{3}{*}{ Size $(\mathrm{cm})$} & $\leq 5.0$ & 395 (55.8\%) & $144(55.2 \%)$ & 251 (56.2\%) & 0.954 \\
\hline & $>5.0$ & $303(42.8 \%)$ & $113(43.3 \%)$ & $190(42.5 \%)$ & \\
\hline & Unknown & $10(1.4 \%)$ & $4(1.5 \%)$ & $6(1.3 \%)$ & \\
\hline \multirow[t]{3}{*}{ Differentiation } & Well-moderate & $654(92.4 \%)$ & 234 (89.7\%) & $420(94.0 \%)$ & 0.038 \\
\hline & Poor & $52(7.3 \%)$ & $25(9.6 \%)$ & $27(6.0 \%)$ & \\
\hline & Unknown & $2(0.3 \%)$ & $2(0.8 \%)$ & $0(0)$ & \\
\hline \multirow[t]{2}{*}{$\mathrm{T}$ category } & 3 & $266(37.6 \%)$ & $120(46.0 \%)$ & 146 (32.7\%) & $<0.001$ \\
\hline & 4 & $442(62.4 \%)$ & $141(54.0 \%)$ & 301 (67.3\%) & \\
\hline \multirow[t]{3}{*}{$\mathrm{CEA}^{\mathrm{b}}(\mathrm{ng} / \mathrm{mL})$} & $<5$ & 388 (54.8\%) & 135 (51.7\%) & $253(56.6 \%)$ & 0.058 \\
\hline & $\geq 5$ & 237 (33.5\%) & 101 (38.7\%) & $136(30.4 \%)$ & \\
\hline & Unknown & $83(11.7 \%)$ & $25(9.6 \%)$ & $58(13.0 \%)$ & \\
\hline \multirow[t]{2}{*}{ Examined lymph nodes } & $<12$ & $186(26.3 \%)$ & 75 (28.7\%) & $111(24.8 \%)$ & 0.255 \\
\hline & $\geq 12$ & $522(73.7 \%)$ & $186(71.3 \%)$ & $336(75.2 \%)$ & \\
\hline \multirow[t]{2}{*}{ Vessel carcinoma embolus } & Negative & $683(96.5 \%)$ & $251(96.2 \%)$ & 432 (96.6\%) & 0.741 \\
\hline & Positive & 25 (3.5\%) & $10(3.8 \%)$ & $15(3.4 \%)$ & \\
\hline \multirow[t]{2}{*}{$\mathrm{CCVD}^{\mathrm{c}}$} & Negative & $616(87.0 \%)$ & 217 (83.1\%) & 399 (89.3\%) & 0.019 \\
\hline & Positive & 92 (13.0\%) & $44(16.9 \%)$ & 48 (10.7\%) & \\
\hline \multirow[t]{2}{*}{$\operatorname{PLR}^{\mathrm{d}}$} & $\leq 130$ & $371(52.4 \%)$ & $134(51.3 \%)$ & 237 (53.0\%) & 0.666 \\
\hline & $>130$ & 337 (47.6\%) & $127(48.7 \%)$ & $210(47.0 \%)$ & \\
\hline
\end{tabular}

${ }^{\mathrm{a}} \mathrm{P}$ value of the Chi-square test

${ }^{\mathrm{b}}$ CEA: carcinoembryonic antigen

c CCVD: cerebrovascular and cardiovascular diseases

d PLR: platelet to lymphocyte ratio 
Table 2 Inflammatory markers of non-chemotherapy and chemotherapy group

\begin{tabular}{|c|c|c|c|c|c|c|c|}
\hline \multirow[t]{3}{*}{ Marker } & \multicolumn{2}{|c|}{ Total } & \multicolumn{2}{|c|}{ Non-chemotherapy } & \multicolumn{2}{|c|}{ Chemotherapy } & \multirow{3}{*}{$\begin{array}{c}\mathrm{P} \\
\text { value }^{\mathrm{a}}\end{array}$} \\
\hline & Median & Interquartile & Median & Interquartile & Median & Interquartile & \\
\hline & & Range & & Range & & Range & \\
\hline $\mathrm{PLR}^{\mathrm{b}}$ & 127.60 & 71.64 & 128.49 & 74.81 & 125.84 & 69.56 & 0.562 \\
\hline $\mathrm{NLR}^{\mathrm{C}}$ & 1.94 & 1.28 & 2.02 & 1.27 & 1.88 & 1.30 & 0.080 \\
\hline $\mathrm{LMR}^{\mathrm{d}}$ & 4.21 & 2.58 & 3.91 & 2.53 & 4.28 & 2.56 & 0.008 \\
\hline $\mathrm{PNI}^{\mathrm{e}}$ & 50.28 & 7.33 & 48.90 & 8.05 & 50.75 & 6.75 & $<0.001$ \\
\hline
\end{tabular}

${ }^{\text {a }} \mathrm{P}$ value of Mann-Whitney $\mathrm{U}$ test

b PLR: platelet to lymphocyte ratio

${ }^{c}$ NLR: neutrophil to lymphocyte ratio

d LMR: lymphocyte to monocyte ratio

e PNI: prognostic nutritional index

Table 3 Overall survival analysis of total patients 


\begin{tabular}{|c|c|c|c|c|c|c|}
\hline \multirow[t]{3}{*}{ Characteristics } & & $\mathrm{RMST}^{\mathrm{b}}(95 \% \mathrm{CI})$ & RMST & $\mathrm{HR}^{\mathrm{c}}(95 \% \mathrm{CI})$ & & Interaction \\
\hline & & Non- & (95\%CI) & & value $^{\mathrm{a}}$ & $\mathrm{p}$ \\
\hline & & chemotherapy & Chemotherapy & & & \\
\hline \multirow[t]{2}{*}{ Total } & & 53.7 (51.9- & $56.2(55.2-$ & $0.580(0.388-$ & 0.007 & - \\
\hline & & $55.2)$ & $57.0)$ & $0.866)$ & & \\
\hline \multirow[t]{4}{*}{ Gender } & Male & 53.2 (50.7- & $55.9(54.4-$ & $0.592(0.360-$ & 0.035 & 0.751 \\
\hline & & $55.1)$ & $57.0)$ & $0.971)$ & & \\
\hline & Female & 54.5 (51.7- & $56.8(54.8-$ & $0.560(0.282-$ & 0.093 & \\
\hline & & $56.4)$ & $58.0)$ & 1.112) & & \\
\hline \multirow[t]{10}{*}{ Age (years) } & $\leq 55$ & $54.3(48.0-$ & 56.3 (53.8- & $0.620(0.225-$ & 0.350 & 0.844 \\
\hline & & 57.6) & $57.8)$ & 1.708) & & \\
\hline & $56-60$ & 55.4 (47.4- & 56.8 (54.4- & 0.725 (0.199- & 0.623 & \\
\hline & & 58.5) & $58.2)$ & $2.634)$ & & \\
\hline & $61-65$ & 53.3 (46.5- & 55.7 (52.9- & $0.636(0.240-$ & 0.357 & \\
\hline & & 56.9) & $57.5)$ & 1.683) & & \\
\hline & $66-70$ & $53.2(48.1-$ & 57.3 (53.6- & $0.355(0.118-$ & 0.053 & \\
\hline & & $56.4)$ & $58.8)$ & 1.063) & & \\
\hline & $>70$ & $53.6(50.9-$ & $54.6(49.5-$ & $0.834(0.371-$ & 0.660 & \\
\hline & & $55.7)$ & $57.1)$ & 1.875) & & \\
\hline \multirow[t]{4}{*}{ Location } & Rectum & $52.2(49.2-$ & 55.6 (53.9- & 0.539 (0.323- & 0.016 & 0.479 \\
\hline & & $54.5)$ & $56.9)$ & $0.900)$ & & \\
\hline & Colon & $55.2(52.8-$ & 56.9 (55.4- & $0.612(0.321-$ & 0.132 & \\
\hline & & 56.9) & $58.1)$ & 1.168) & & \\
\hline \multirow[t]{4}{*}{ Size (cm) } & $\leq 5.0$ & $54.0(51.2-$ & $56.1(54.5-$ & $0.621(0.361-$ & 0.081 & 0.255 \\
\hline & & $55.8)$ & $57.2)$ & 1.067) & & \\
\hline & $>5.0$ & $53.7(50.5-$ & $56.3(54.5-$ & $0.561(0.306-$ & 0.058 & \\
\hline & & $55.8)$ & $57.5)$ & 1.028) & & \\
\hline \multirow[t]{4}{*}{ Differentiation } & Well- & $53.9(52.0-$ & 56.3 (55.2- & 0.569 (0.373- & 0.008 & 0.396 \\
\hline & moderate & $55.4)$ & $57.2)$ & $0.868)$ & & \\
\hline & Poor & $52.0(43.2-$ & 54.7 (46.8- & 0.662 (0.177- & 0.534 & \\
\hline & & 56.6) & $57.8)$ & $2.471)$ & & \\
\hline \multirow[t]{4}{*}{$\mathrm{T}$ category } & 3 & 56.4 (53.7- & $57.6(55.5-$ & $0.654(0.277-$ & 0.328 & 0.382 \\
\hline & & $58.0)$ & $58.6)$ & 1.543) & & \\
\hline & 4 & $51.8(49.2-$ & $55.6(54.2-$ & $0.501(0.318-$ & 0.002 & \\
\hline & & 54.0) & $56.8)$ & $0.791)$ & & \\
\hline $\mathrm{CEA}^{\mathrm{d}}(\mathrm{ng} / \mathrm{mL})$ & $<5$ & $54.6(51.9-$ & 56.7 (55.3- & $0.585(0.323-$ & 0.073 & 0.482 \\
\hline
\end{tabular}




\begin{tabular}{|c|c|c|c|c|c|c|}
\hline & & $56.4)$ & $57.8)$ & 1.060) & & \\
\hline & $\geq 5$ & $53.5(50.1-$ & 55.1 (52.8- & $0.734(0.384-$ & 0.348 & \\
\hline & & $55.7)$ & $56.8)$ & 1.404) & & \\
\hline \multirow{4}{*}{$\begin{array}{c}\text { Examined lymph } \\
\text { nodes }\end{array}$} & $<12$ & 52.0 & 53.6 (50.2- & $0.793(0.414-$ & 0.483 & 0.415 \\
\hline & & 54.9) & 55.6) & 1.520) & & \\
\hline & $\geq 12$ & 54.5 (52.3- & 57.1 (55.9- & $0.500(0.300-$ & 0.007 & \\
\hline & & $56.0)$ & 57.9) & $0.835)$ & & \\
\hline \multirow[t]{4}{*}{$\operatorname{PLR}^{\mathrm{e}}$} & $\leq 130$ & 56.0 & 56.0 & 0.983 (0.528- & 0.956 & 0.027 \\
\hline & & $57.6)$ & $57.2)$ & 1.829) & & \\
\hline & $>130$ & 51.3 (47.8- & 56.5 (54.8- & $0.371(0.212-$ & $<0.001$ & \\
\hline & & $53.7)$ & $57.7)$ & 0.649) & & \\
\hline
\end{tabular}

${ }^{\text {a }} \mathrm{P}$ value of the log-rank test

${ }^{b}$ RMST: the restricted mean survival time

${ }^{c}$ HR: Hazard Ratio, chemotherapy patients vs. non-chemotherapy patients

${ }^{\mathrm{d}}$ CEA: carcinoembryonic antigen

e PLR: platelet to lymphocyte ratio

Table 4 Characteristics of non-chemotherapy and chemotherapy group after PSM 


\begin{tabular}{|c|c|c|c|c|c|}
\hline \multirow[t]{2}{*}{ Characteristics } & \multirow{2}{*}{\multicolumn{2}{|c|}{$\begin{array}{c}\text { Total } \\
332\end{array}$}} & \multirow{2}{*}{$\begin{array}{c}\text { Non-chemotherapy } \\
166\end{array}$} & \multirow{2}{*}{$\begin{array}{c}\text { Chemotherapy } \\
166\end{array}$} & \multirow[t]{2}{*}{$\mathrm{P}$ value ${ }^{\mathrm{a}}$} \\
\hline & & & & & \\
\hline \multirow[t]{2}{*}{ Gender } & Male & 199 (59.9\%) & 97 (58.4\%) & $102(61.4 \%)$ & 0.575 \\
\hline & Female & $133(40.1 \%)$ & $69(41.6 \%)$ & $64(38.6 \%)$ & \\
\hline \multirow[t]{5}{*}{ Age (years) } & $\leq 55$ & $58(17.4 \%)$ & $30(18.1 \%)$ & $28(16.9 \%)$ & 0.879 \\
\hline & $56-60$ & $42(12.7 \%)$ & $20(12.0 \%)$ & $22(13.2 \%)$ & \\
\hline & $61-65$ & $65(19.6 \%)$ & $32(19.3 \%)$ & $33(19.9 \%)$ & \\
\hline & $66-70$ & $74(22.3 \%)$ & $34(20.5 \%)$ & $40(24.1 \%)$ & \\
\hline & $>70$ & $93(28.0 \%)$ & 50 (30.1\%) & 43 (25.9\%) & \\
\hline \multirow[t]{2}{*}{ Location } & Rectum & 171 (51.5\%) & 88 (53.0\%) & $83(50.0 \%)$ & 0.583 \\
\hline & Colon & $161(48.5 \%)$ & $78(47.0 \%)$ & $83(50.0 \%)$ & \\
\hline \multirow[t]{3}{*}{ Size $(\mathrm{cm})$} & $\leq 5.0$ & $183(55.1 \%)$ & $92(55.4 \%)$ & 91 (54.8\%) & 0.833 \\
\hline & $>5.0$ & $143(44.0 \%)$ & $72(43.4 \%)$ & $74(44.6 \%)$ & \\
\hline & Unknown & $3(0.9 \%)$ & $2(1.2 \%)$ & $1(0.6 \%)$ & \\
\hline \multirow[t]{2}{*}{ Differentiation } & Well-moderate & $309(93.1 \%)$ & $154(92.8 \%)$ & $155(93.4 \%)$ & 0.829 \\
\hline & Poor & $23(6.9 \%)$ & $12(7.2 \%)$ & $11(6.6 \%)$ & \\
\hline \multirow[t]{2}{*}{$\mathrm{T}$ category } & 3 & $127(38.3 \%)$ & $62(37.3 \%)$ & $65(39.2 \%)$ & 0.735 \\
\hline & 4 & $205(61.7 \%)$ & $104(62.7 \%)$ & $101(60.8 \%)$ & \\
\hline \multirow[t]{3}{*}{$\mathrm{CEA}^{\mathrm{b}}(\mathrm{ng} / \mathrm{mL})$} & $<5$ & $175(52.7 \%)$ & $88(53.0 \%)$ & $87(52.4 \%)$ & 0.968 \\
\hline & $\geq 5$ & $118(35.5 \%)$ & $58(34.9 \%)$ & $60(36.1 \%)$ & \\
\hline & Unknown & $39(11.8 \%)$ & $20(12.1 \%)$ & $19(11.5 \%)$ & \\
\hline \multirow[t]{2}{*}{ Examined lymph nodes } & $<12$ & $84(25.3 \%)$ & $41(24.7 \%)$ & $43(25.9 \%)$ & 0.801 \\
\hline & $\geq 12$ & $248(74.7 \%)$ & $125(75.3 \%)$ & $123(74.1 \%)$ & \\
\hline \multirow[t]{2}{*}{ Vessel carcinoma embolus } & Negative & $320(96.4 \%)$ & $160(96.4 \%)$ & $160(96.4 \%)$ & 1.000 \\
\hline & Positive & $12(3.6 \%)$ & $6(3.6 \%)$ & $6(3.6 \%)$ & \\
\hline \multirow[t]{2}{*}{$\mathrm{CCVD}^{\mathrm{c}}$} & Negative & $287(86.4 \%)$ & $147(88.6 \%)$ & $140(84.3 \%)$ & 0.262 \\
\hline & Positive & $45(13.6 \%)$ & $19(11.4 \%)$ & $26(15.7 \%)$ & \\
\hline \multirow[t]{2}{*}{$\mathrm{PLR}^{\mathrm{d}}$} & $\leq 130$ & $176(53.0 \%)$ & $85(51.2 \%)$ & $91(54.8 \%)$ & 0.509 \\
\hline & $>130$ & $156(47.0 \%)$ & $81(48.8 \%)$ & $75(45.2 \%)$ & \\
\hline
\end{tabular}

a $\mathrm{P}$ value of the Chi-square test

${ }^{b}$ CEA: carcinoembryonic antigen

${ }^{c}$ CCVD: cerebrovascular and cardiovascular diseases

${ }^{d}$ PLR: platelet to lymphocyte ratio 
Table 5 Overall survival analysis of patients after PSM

Page 19/29 


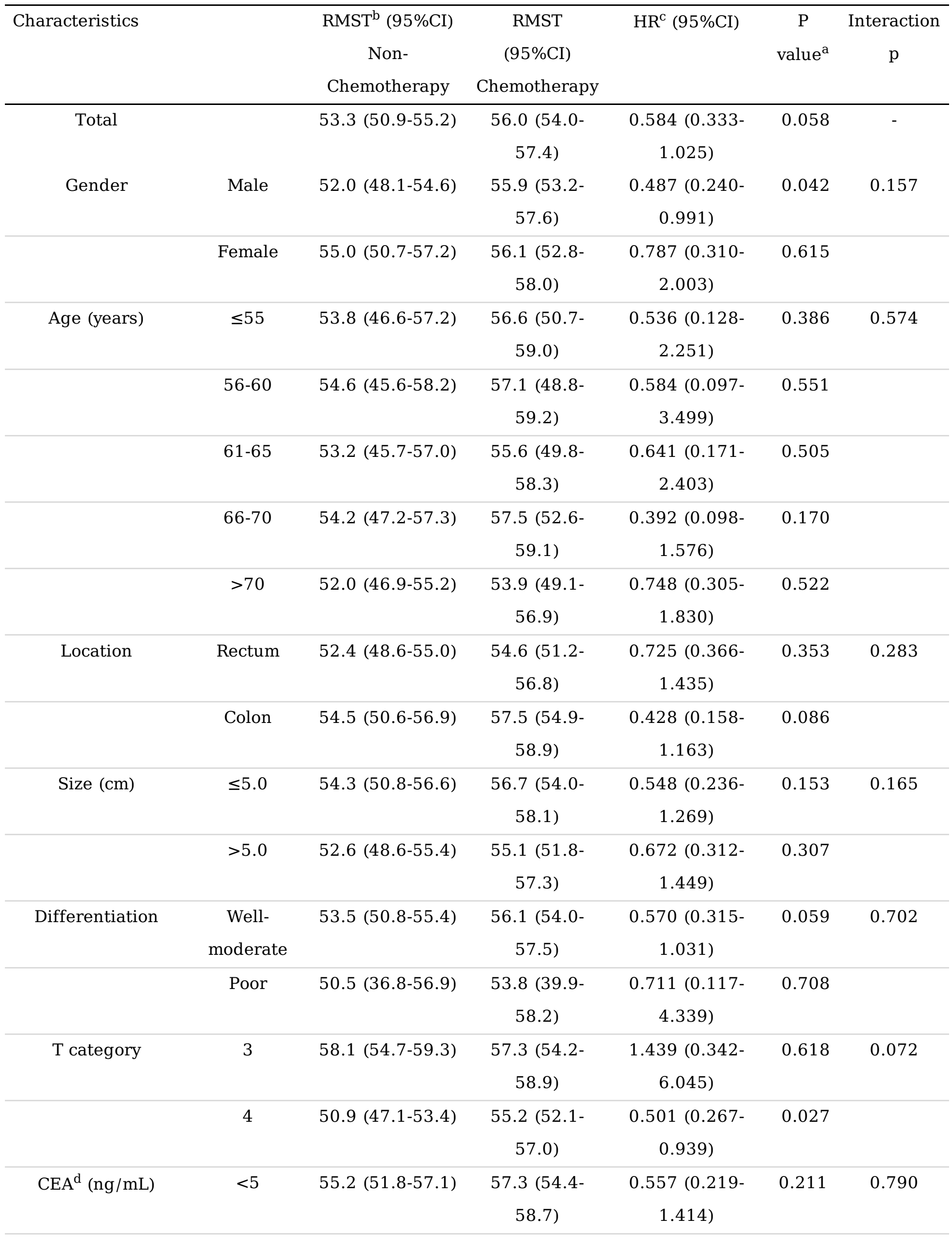




\begin{tabular}{|c|c|c|c|c|c|c|}
\hline & $\geq 5$ & $52.4(46.8-55.7)$ & $\begin{array}{c}55.0(51.0- \\
57.4)\end{array}$ & $\begin{array}{c}0.641(0.265- \\
1.552)\end{array}$ & 0.320 & \\
\hline \multirow[t]{2}{*}{$\begin{array}{c}\text { Examined lymph } \\
\text { nodes }\end{array}$} & $<12$ & $50.7(44.5-54.8)$ & $\begin{array}{c}51.7(46.5- \\
55.1)\end{array}$ & $\begin{array}{c}0.898(0.381- \\
2.118)\end{array}$ & 0.806 & 0.322 \\
\hline & $\geq 12$ & $54.1(51.4-56.0)$ & $\begin{array}{c}57.5(55.5- \\
58.7)\end{array}$ & $\begin{array}{c}0.404(0.185- \\
0.882)\end{array}$ & 0.018 & \\
\hline \multirow[t]{2}{*}{$\mathrm{PLR}^{\mathrm{e}}$} & $\leq 130$ & $55.3(51.8-57.4)$ & $\begin{array}{c}54.9(52.0- \\
56.8)\end{array}$ & $\begin{array}{c}1.080(0.495- \\
2.355)\end{array}$ & 0.847 & 0.038 \\
\hline & $>130$ & $51.3(47.2-54.2)$ & $\begin{array}{c}57.6(54.2- \\
59.0)\end{array}$ & $\begin{array}{c}0.272(0.102- \\
0.726)\end{array}$ & 0.005 & \\
\hline
\end{tabular}

${ }^{\text {a }} \mathrm{P}$ value of the log-rank test

${ }^{b}$ RMST: the restricted mean survival time

${ }^{c}$ HR: Hazard Ratio, chemotherapy patients vs. non-chemotherapy patients

d CEA: carcinoembryonic antigen

e PLR: platelet to lymphocyte ratio

Table 6 Cancer-specific survival analysis of total patients 


\begin{tabular}{|c|c|c|c|c|c|c|}
\hline \multirow[t]{3}{*}{ Characteristics } & & \multirow{3}{*}{$\begin{array}{l}\text { RMST }^{\mathrm{b}}(95 \% \mathrm{CI}) \\
\text { Non- } \\
\text { chemotherapy }\end{array}$} & \multirow{3}{*}{$\begin{array}{c}\text { RMST } \\
(95 \% \mathrm{CI}) \\
\text { Chemotherapy }\end{array}$} & \multirow[t]{3}{*}{$\mathrm{HR}^{\mathrm{C}}(95 \% \mathrm{CI})$} & \multirow{3}{*}{$\begin{array}{c}\mathrm{P} \\
\text { value }^{\mathrm{a}}\end{array}$} & \multirow{3}{*}{$\begin{array}{c}\text { Interaction } \\
\mathrm{p}\end{array}$} \\
\hline & & & & & & \\
\hline & & & & & & \\
\hline \multirow[t]{2}{*}{ Total } & & 53.8 (51.7- & $56.2(50.1-$ & $0.673(0.412-$ & 0.112 & - \\
\hline & & $55.3)$ & $57.1)$ & $1.101)$ & & \\
\hline \multirow[t]{4}{*}{ Gender } & Male & $53.2(50.7-$ & $55.9(54.4-$ & $0.598(0.330-$ & 0.086 & 0.393 \\
\hline & & $55.3)$ & $57.1)$ & $1.084)$ & & \\
\hline & Female & 54.5 (51.3- & $56.8(55.0-$ & $0.882(0.365-$ & 0.781 & \\
\hline & & $56.5)$ & $58.0)$ & $2.134)$ & & \\
\hline \multirow[t]{10}{*}{ Age (years) } & $\leq 55$ & 54.3 & $56.3(54.2-$ & 0.669 (0.218- & 0.479 & 0.986 \\
\hline & & $57.4)$ & $57.7)$ & $2.053)$ & & \\
\hline & $56-60$ & $55.4(47.4-$ & $56.8(54.2-$ & $0.656(0.132-$ & 0.602 & \\
\hline & & $58.5)$ & $58.3)$ & $3.250)$ & & \\
\hline & $61-65$ & 53.3 & 55.7 (52.8- & $0.720(0.224-$ & 0.519 & \\
\hline & & $57.0)$ & $57.4)$ & 2.314) & & \\
\hline & $66-70$ & $53.2(48.2-$ & 57.3 (53.7- & $0.172(0.036-$ & 0.013 & \\
\hline & & $56.3)$ & $58.8)$ & $0.834)$ & & \\
\hline & $>70$ & $53.6(50.6-$ & $54.6(50.0-$ & $1.240(0.458-$ & 0.671 & \\
\hline & & $55.8)$ & $57.2)$ & 3.356) & & \\
\hline \multirow[t]{4}{*}{ Location } & Rectum & $52.2(49.2-$ & 55.6 (53.8- & $0.586(0.311-$ & 0.094 & 0.445 \\
\hline & & $54.5)$ & 56.9) & $1.105)$ & & \\
\hline & Colon & $55.2(52.6-$ & 56.9 (55.4- & $0.775(0.355-$ & 0.521 & \\
\hline & & 56.9) & $58.0)$ & 1.691) & & \\
\hline \multirow[t]{4}{*}{ Size $(\mathrm{cm})$} & $\leq 5.0$ & 54.0 (51.3- & $56.1(54.6-$ & 0.737 (0.389- & 0.347 & 0.154 \\
\hline & & 55.9) & $57.2)$ & 1.396) & & \\
\hline & $>5.0$ & 53.7 (50.4- & 56.3 (54.4- & $0.638(0.289-$ & 0.262 & \\
\hline & & $55.8)$ & $57.5)$ & $1.408)$ & & \\
\hline \multirow[t]{4}{*}{ Differentiation } & Well- & 53.9 (51.9- & $56.3(55.1-$ & $0.685(0.406-$ & 0.154 & 0.548 \\
\hline & moderate & $55.4)$ & $57.2)$ & 1.157) & & \\
\hline & Poor & $52.0(43.1-$ & $54.7(47.5-$ & $0.625(0.139-$ & 0.535 & \\
\hline & & $56.2)$ & $58.1)$ & $2.805)$ & & \\
\hline \multirow[t]{4}{*}{$\mathrm{T}$ category } & 3 & 56.4 (54.1- & 57.6 (55.4- & 0.797 (0.307- & 0.640 & 0.377 \\
\hline & & $58.0)$ & $58.7)$ & 2.069) & & \\
\hline & 4 & 51.8 & $55.6(54.2-$ & 0.579 (0.326- & 0.059 & \\
\hline & & $54.0)$ & 56.7) & 1.030) & & \\
\hline $\mathrm{CEA}^{\mathrm{d}}(\mathrm{ng} / \mathrm{mL})$ & $<5$ & 54.6 (51.9- & 56.8 (55.3- & $0.774(0.376-$ & 0.487 & 0.554 \\
\hline
\end{tabular}




\begin{tabular}{|c|c|c|c|c|c|c|}
\hline & & 56.6) & $57.8)$ & 1.596) & & \\
\hline & $\geq 5$ & 53.5 & 55.1 (52.6- & $0.682(0.300-$ & 0.357 & \\
\hline & & $55.7)$ & $56.8)$ & 1.549) & & \\
\hline \multirow{4}{*}{$\begin{array}{c}\text { Examined lymph } \\
\text { nodes }\end{array}$} & $<12$ & 52.0 & 53.6 (50.4- & 0.906 (0.407- & 0.810 & 0.517 \\
\hline & & 54.9) & $55.7)$ & 2.018) & & \\
\hline & $\geq 12$ & 54.4 & 57.1 & 0.590 & 0.094 & \\
\hline & & $56.1)$ & 57.9) & 1.102) & & \\
\hline \multirow[t]{4}{*}{$\mathrm{PLR}^{\mathrm{e}}$} & $\leq 130$ & 56.0 & 56.0 & $1.016(0.494-$ & 0.967 & 0.116 \\
\hline & & 57.6) & $57.1)$ & 2.087) & & \\
\hline & $>130$ & 51.3 & 56.5 & 0.440 & 0.019 & \\
\hline & & $53.8)$ & $57.8)$ & 0.893) & & \\
\hline
\end{tabular}

${ }^{\text {a }} \mathrm{P}$ value of the log-rank test

${ }^{b}$ RMST: the restricted mean survival time

${ }^{c}$ HR: Hazard Ratio, chemotherapy patients vs. non-chemotherapy patients

${ }^{d}$ CEA: carcinoembryonic antigen

e PLR: platelet to lymphocyte ratio

Table 7 Cancer-specific survival analysis of patients after PSM 


\begin{tabular}{|c|c|c|c|c|c|c|}
\hline \multirow[t]{3}{*}{ Characteristics } & & $\mathrm{RMST}^{\mathrm{b}}(95 \% \mathrm{CI})$ & RMST & $\mathrm{HR}^{\mathrm{C}}(95 \% \mathrm{CI})$ & & Interaction \\
\hline & & Non- & $(95 \% \mathrm{CI})$ & & value $^{\mathrm{a}}$ & $\mathrm{p}$ \\
\hline & & chemotherapy & Chemotherapy & & & \\
\hline \multirow[t]{2}{*}{ Total } & & $53.3(51.0-$ & 56.0 & $0.684(0.332-$ & 0.300 & - \\
\hline & & $55.1)$ & $57.5)$ & 1.409) & & \\
\hline \multirow[t]{4}{*}{ Gender } & Male & 52.0 & 55.9 (53.2- & $0.420(0.169-$ & 0.053 & 0.026 \\
\hline & & $54.6)$ & $57.7)$ & 1.042) & & \\
\hline & Female & $55.0(51.1-$ & $56.1(52.2-$ & $1.926(0.478-$ & 0.349 & \\
\hline & & 57.3) & 57.9) & 7.762) & & \\
\hline \multirow[t]{10}{*}{ Age (years) } & $\leq 55$ & 53.8 & $56.6(50.4-$ & $0.435(0.079-$ & 0.324 & 0.196 \\
\hline & & $57.4)$ & 58.9) & $2.388)$ & & \\
\hline & $56-60$ & 54.6 (45.3- & 57.1 (49.9- & $0.458(0.041-$ & 0.513 & \\
\hline & & $58.2)$ & $59.2)$ & $5.054)$ & & \\
\hline & $61-65$ & 53.2 (46.3- & 55.6 (48.5- & 0.789 (0.158- & 0.772 & \\
\hline & & $57.0)$ & $58.1)$ & 3.949) & & \\
\hline & $66-70$ & 54.2 & 57.5 (52.7- & $0.182(0.020-$ & 0.086 & \\
\hline & & $57.3)$ & $59.1)$ & 1.645) & & \\
\hline & $>70$ & $52.0(47.2-$ & 53.9 (48.5- & $1.660(0.468-$ & 0.427 & \\
\hline & & $55.3)$ & $56.5)$ & $5.887)$ & & \\
\hline \multirow[t]{4}{*}{ Location } & Rectum & 52.4 (48.7- & 54.6 (51.3- & 0.738 (0.297- & 0.511 & 0.797 \\
\hline & & $54.9)$ & $56.8)$ & 1.836) & & \\
\hline & Colon & 54.5 (50.3- & $57.5(54.8-$ & 0.634 (0.192- & 0.449 & \\
\hline & & $56.8)$ & $58.8)$ & $2.087)$ & & \\
\hline \multirow[t]{4}{*}{ Size $(\mathrm{cm})$} & $\leq 5.0$ & 54.3 (50.6- & 56.7 (54.0- & $0.846(0.295-$ & 0.756 & 0.116 \\
\hline & & 56.5) & $58.2)$ & 2.425) & & \\
\hline & $>5.0$ & 52.6 (48.8- & 55.1 (51.6- & $0.641(0.228-$ & 0.395 & \\
\hline & & $55.5)$ & $57.3)$ & 1.802) & & \\
\hline \multirow[t]{4}{*}{ Differentiation } & Well- & 53.5 (50.8- & 56.1 (54.2- & 0.703 (0.329- & 0.361 & 0.864 \\
\hline & moderate & $55.5)$ & $57.5)$ & $1.504)$ & & \\
\hline & Poor & 50.5 (36.0- & 53.8 (38.2- & $0.574(0.050-$ & 0.651 & \\
\hline & & $56.7)$ & $58.6)$ & $6.560)$ & & \\
\hline \multirow[t]{4}{*}{$\mathrm{T}$ category } & 3 & 58.1 (54.1- & 57.3 (54.3- & 3.306 (0.367- & 0.258 & 0.042 \\
\hline & & 59.4) & 58.9) & 29.738) & & \\
\hline & 4 & 50.9 (47.3- & 55.2 (52.3- & $0.517(0.228-$ & 0.107 & \\
\hline & & 53.6) & $57.0)$ & 1.172) & & \\
\hline $\mathrm{CEA}^{\mathrm{d}}(\mathrm{ng} / \mathrm{mL})$ & $<5$ & 55.2 & 57.3 (54.3- & $0.785(0.239-$ & 0.688 & 0.897 \\
\hline
\end{tabular}




\begin{tabular}{|c|c|c|c|c|c|c|}
\hline & $\geq 5$ & $\begin{array}{c}52.4(47.5- \\
55.8)\end{array}$ & $\begin{array}{c}55.0(51.4- \\
57.2)\end{array}$ & $\begin{array}{c}0.667(0.203- \\
2.195)\end{array}$ & 0.502 & \\
\hline \multirow[t]{2}{*}{$\begin{array}{c}\text { Examined lymph } \\
\text { nodes }\end{array}$} & $<12$ & $\begin{array}{c}50.7(43.8- \\
54.8)\end{array}$ & $\begin{array}{c}51.7(45.5- \\
55.2)\end{array}$ & $\begin{array}{c}1.620(0.487- \\
5.393)\end{array}$ & 0.427 & 0.107 \\
\hline & $\geq 12$ & $\begin{array}{c}54.1(51.1- \\
56.0)\end{array}$ & $\begin{array}{c}57.5(55.6- \\
58.7)\end{array}$ & $\begin{array}{c}0.359(0.128- \\
1.007)\end{array}$ & 0.042 & \\
\hline \multirow[t]{2}{*}{$\mathrm{PLR}^{\mathrm{e}}$} & $\leq 130$ & $\begin{array}{c}55.3(51.8- \\
57.4)\end{array}$ & $\begin{array}{c}54.9(51.9- \\
56.8)\end{array}$ & $\begin{array}{c}0.963(0.379- \\
2.449)\end{array}$ & 0.938 & 0.231 \\
\hline & $>130$ & $\begin{array}{c}51.3(47.4- \\
54.1)\end{array}$ & $\begin{array}{c}57.6(54.7- \\
58.9)\end{array}$ & $\begin{array}{c}0.372(0.100- \\
1.374)\end{array}$ & 0.122 & \\
\hline
\end{tabular}

${ }^{\text {a }} \mathrm{P}$ value of the log-rank test

${ }^{\mathrm{b}}$ RMST: the restricted mean survival time

${ }^{c}$ HR: Hazard Ratio, chemotherapy patients vs. non-chemotherapy patients

${ }^{\mathrm{d}}$ CEA: carcinoembryonic antigen

e PLR: platelet to lymphocyte ratio

\section{Figures}
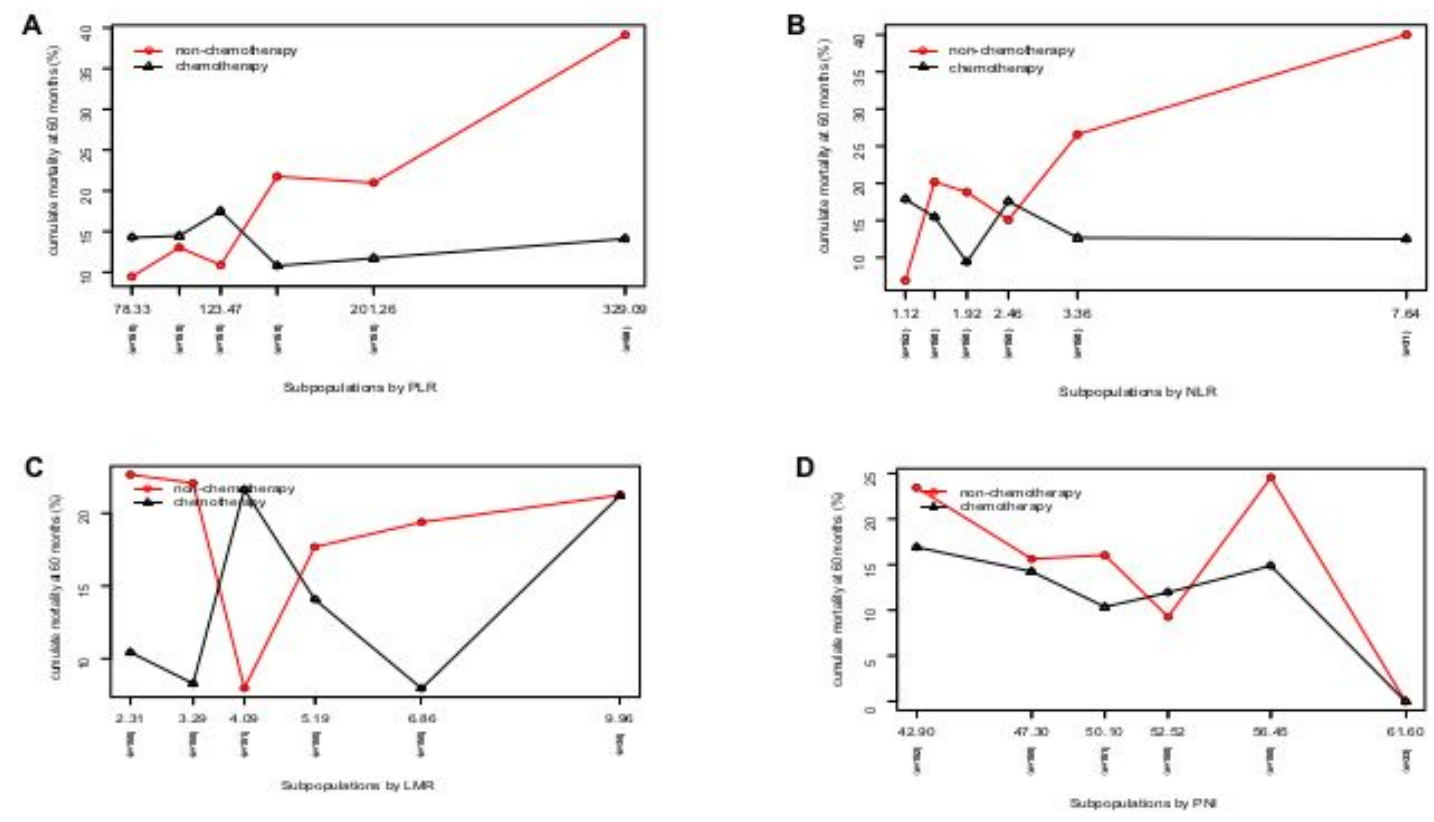

\section{Figure 1}

STEPP analysis of the concerned inflammatory markers. (A) The result of PLR. (B) The result of NLR. (C) The result of LMR. (D) The result of PNI. 

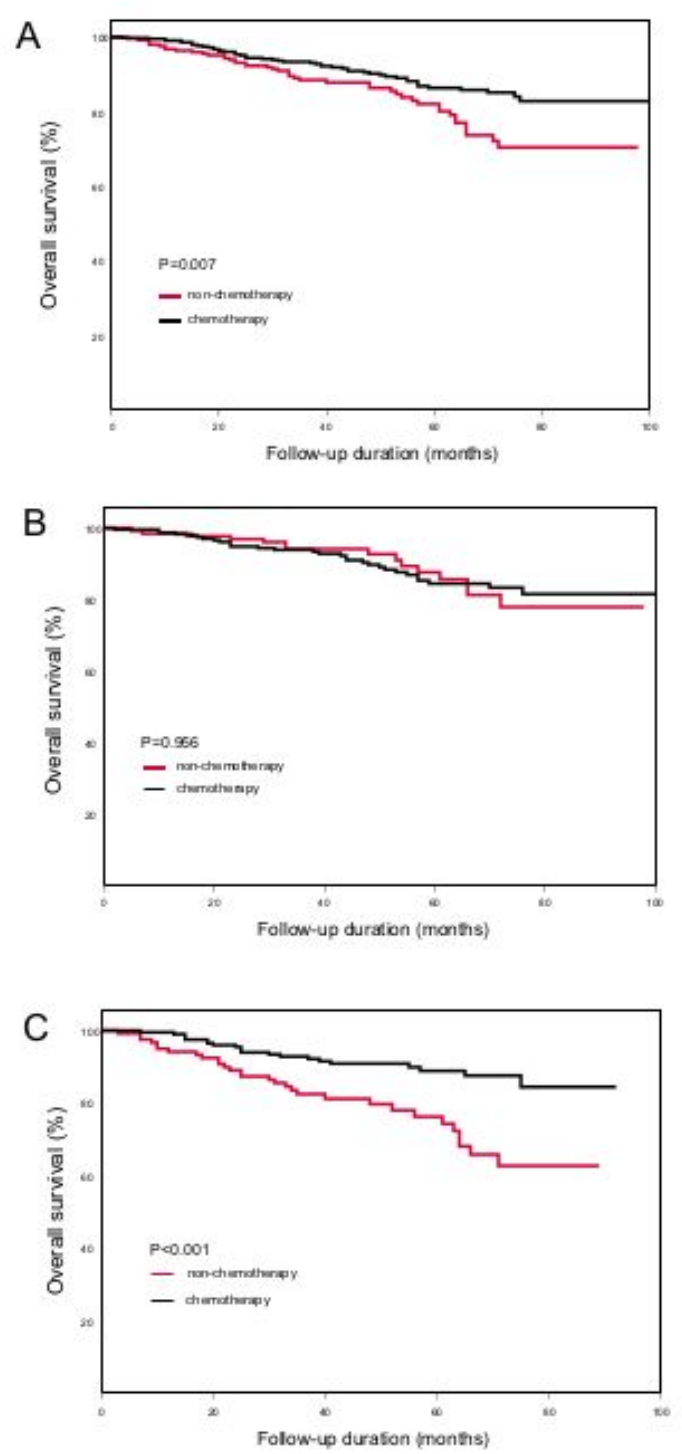

\section{Figure 2}

Kaplan-Meier overall survival curve of stage $\triangle \mathrm{CRC}$ patients. (A) The result of total patients. (B) The result of low-PLR subgroup. (C) The result of high-PLR subgroup. 
A

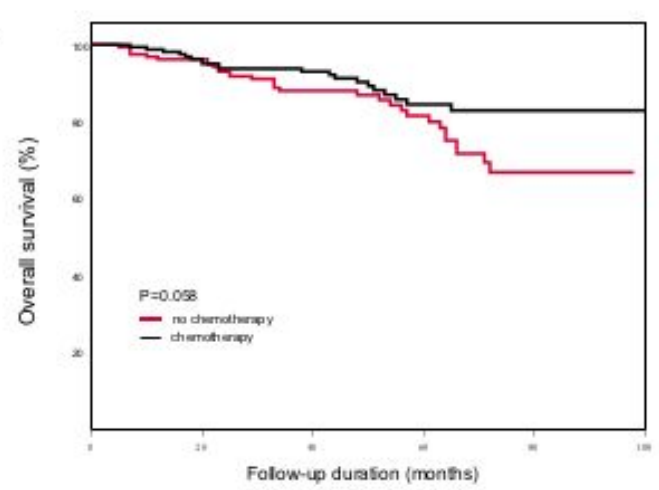

B

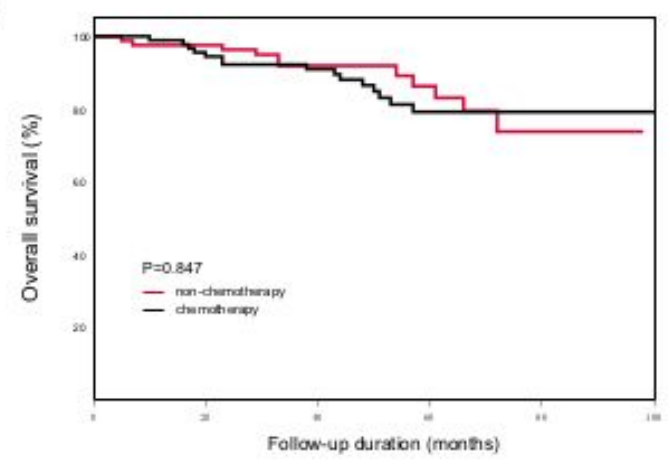

C

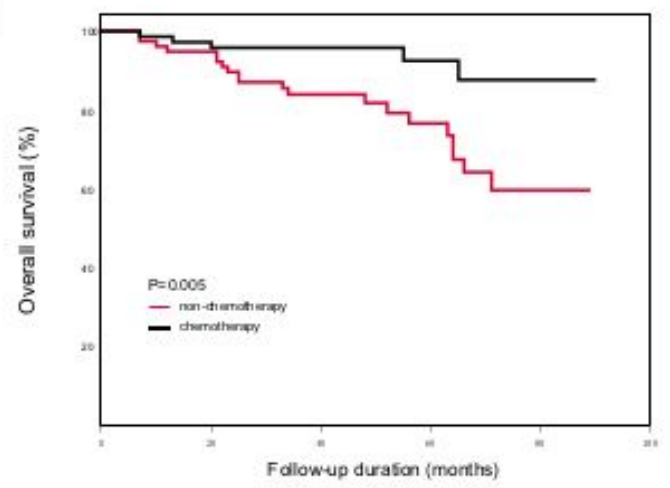

\section{Figure 3}

Kaplan-Meier overall survival curve of stage $\otimes$ CRC patients after PSM. (A) The result of total patients. (B) The result of lowPLR subgroup. (C) The result of high-PLR subgroup. 

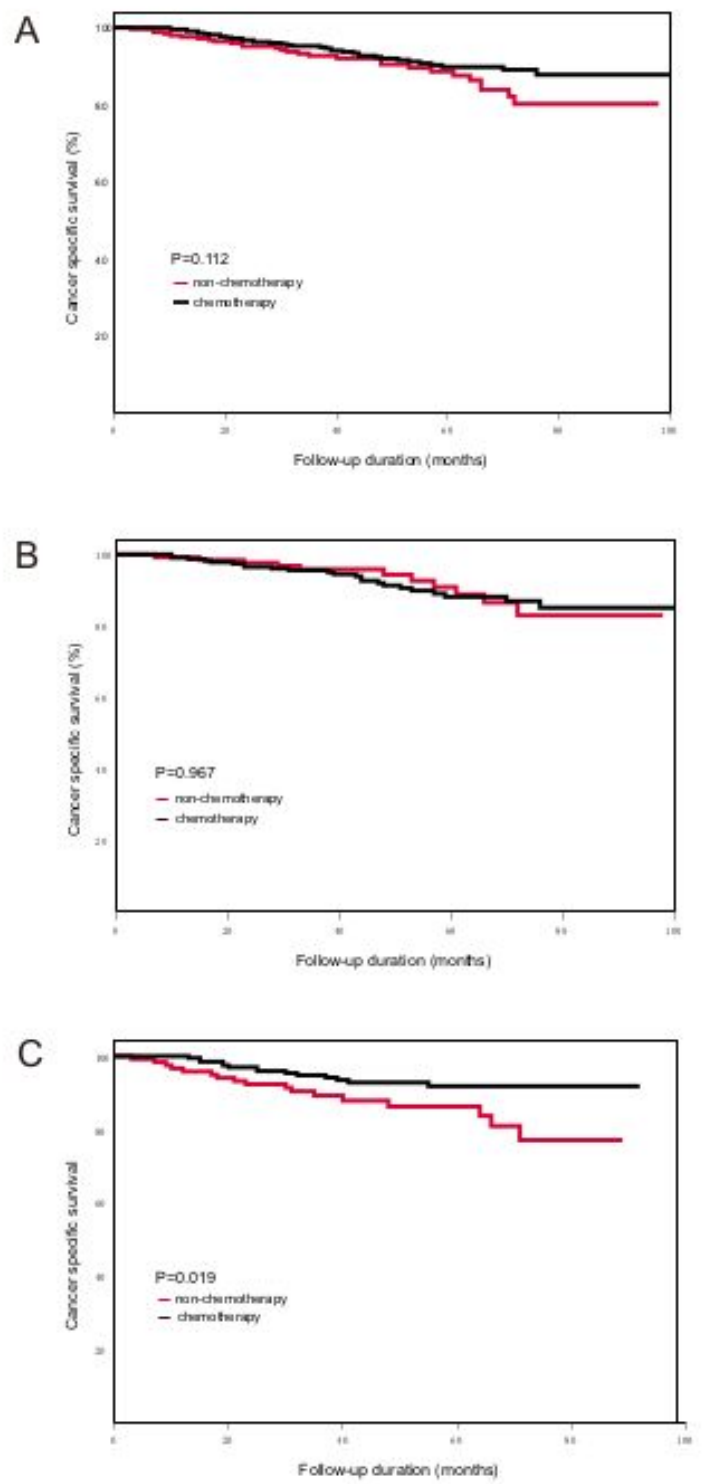

\section{Figure 4}

Kaplan-Meier cancer-specific survival curve of stage II CRC patients. (A) The result of total patients. (B) The result of lowPLR subgroup. (C) The result of high-PLR subgroup. 
A

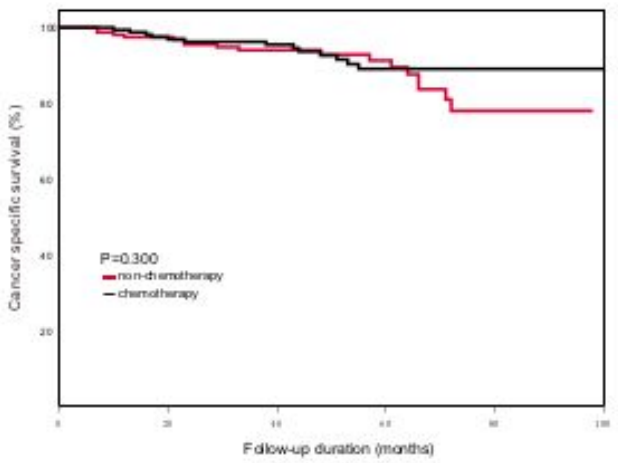

B

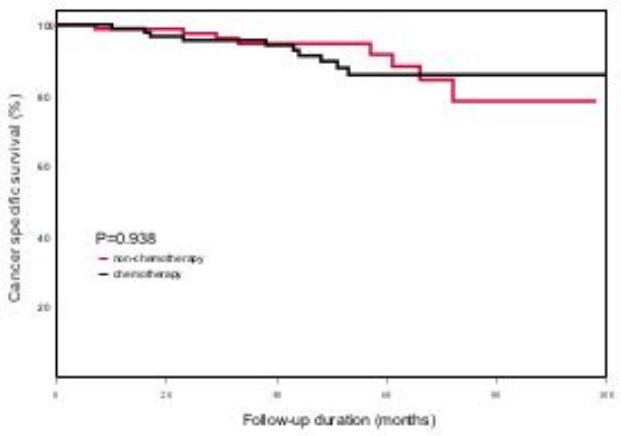

C

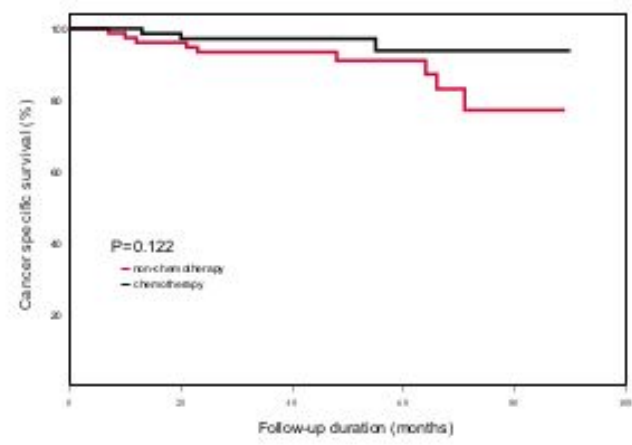

\section{Figure 5}

Kaplan-Meier cancer-specific survival curve of stage II CRC patients after PSM. (A) The result of total patients. (B) The result of low-PLR subgroup. (C) The result of high-PLR subgroup.

\section{Supplementary Files}

This is a list of supplementary files associated with this preprint. Click to download.

- Additionalfiles.docx

- Additionalfile1.xIsx

- Additionalfile2.xlsx 